\title{
The Teaching of Usability in Software Development: Case Study in the Computer Engineering Career at the University of Matanzas
}

\author{
https://doi.org/10.3991/ijep.v11i1.14837 \\ Josue Segura \\ University of Matanzas, Matanzas, Cuba \\ josue.segura@mtz.jovenclub.cu
}

\begin{abstract}
The Cuban software industry is currently demanding the development of higher quality, more usable products that provide a better experience for end users. Usability Engineering (UE) promotes the early evaluation of usability in the software development process and user participation in all phases of the life cycle. In order to know the treatment that is given to the Usability in Software Development (USD) in the Computer Engineering degree at the University of Matanzas, an exploratory study was carried out, using methods of the theoretical and empirical level. A review of the international scientific literature related to the subject and the normative documents that govern the degree was carried out as well as interviews with professors and students in order to verify the treatment given to the USD. A case study is presented where aspects related to the subject are deepened proposing the inclusion in the optional curriculum of the degree course "Usability in software development". The results showed the appropriation of the knowledge of the group of students who received the subject. It enabled them to develop prototypes of the system of higher quality and more usability. The need to expand topics that include the end-user experience when interacting with the software as a guarantee of product quality is concluded, guaranteeing from the university curriculum the preparation of professionals in this area of scientific knowledge.
\end{abstract}

Keywords-Usability, Software, Developments, Computer, Engineering

\section{Introduction}

Today, thanks to advances in computing, software is found in different and diverse fields of human activity, making it highly necessary that it meets quality criteria to largely satisfy the needs of users. In defining software quality, a distinction must be made between the quality of the software product and the quality of the development process. However, the goals that are set for the quality of the product will determine the goals to be set for the quality of the development process. The success or failure of a software product is largely determined by the quality of performance of their interfaces. For this reason, developers and designers must pay special attention to this element as one of the essential parts of the product [1]. 
The inclusion of usability in software engineering has been considered as one more quality attribute by several authors. [1]-[7]. [2]consider that the inclusion of usability in Software engineering is not something new and has been considered as one more quality attribute, but it has been omitted or has been considered little, since its inception, to focus only on attributes such as reliability, efficiency and reliability.[5], [6] state that usability is one of the quality characteristics that has gained greater relevance in the software industry over the years. That is why it is important that current software engineering incorporates usability into existing development methodologies. Usability has been addressed by several authors and international standards have been established in this regard, usability is defined as the ability of a software to be understood, learned, used and attractive for to the user, under specific conditions of use[8]. For the ISO 9241 standard, which deals with ergonomic requirements, usability is "the degree to which a product can be used by specific users to achieve specific objectives with effectiveness, efficiency and satisfaction in a given context of use"[9]. Currently one of the most accepted concepts is that[10], the definition of usability for this international standard recognizes among its sub-characteristics the objective recognition, learning, operability, protection against errors, aesthetics of the user interface and accessibility.

On the other hand, Usability Engineering is the discipline oriented to the approach the development of systems in which quantitative levels of usability are specified a priori, and the system is built to reach said levels, which are known as metrics [8]. Engineering Usability provides a practical way to ensure that the software developed reaches a certain level of usability and is based on evaluation through usability tests with users. Making use of the sub-characteristics and usability attributes to satisfy the software requirements to be carried out.

In Cuba, actions are carried out aimed at complying with the comprehensive policy for the improvement of the computerization of society. This policy is supported on the basis of the National Plan for Economic and Social Development until 2030 mentioned in Guideline 108 [11]. The Cuban State has declared its interest in these processes, which are a priority in the government of the country, for which the issues of the quality of products and services are addressed to guarantee their correspondence with international standards. Through Guideline number 83 instructions taken into account by quality evaluating and / or certifying entities are required, which are also present in the Cuban software industry.

On the other hand, in the Cuban academic environment[6], [12], [13] spaces for exchange between professionals in software engineering are developed. These allow the dissemination of research related to the inclusion of Usability Engineering in the software development process. In all these works, it is observed that Cuban researchers pay attention to the assurance and evaluation of usability, denoting the importance they pay to usability engineering at all stages of software development, however, the scientific literature consulted shows little treatment of usability engineering teaching and its integration with traditional software engineering in the current Cuban academic context. Among the disciplines that contribute to this achievement is the Software Engineering and Management discipline, which among its general objectives is to develop software management processes, ensuring the quality of computer products. Due to the rapid development of computing and given objectives of this discipline it is difficult to define 
the optional subjects, in this sense the study plans set out some topics that, in light of the current situation, are important proposals, among which the quality of the software stands out.

It is important to highlight that among the general objectives to be achieved by graduates of the Computer Engineering degree in Cuba approved in the study plan E they refer to: Carry out their work with professionalism, with permanent attention to the quality of their results, which will be fundamentally given by the application of the best practices and international standards of software engineering. In this sense, the Study Plan E of the Computer Engineering career is based on the experience acquired in the realization of economic and social transformations that occurred in Cuba, which contribute to the definition of the Professional model of the career and that imposed the improvement of the curricula.

The University of Matanzas is part of the network of Cuban Higher Education Centers (HEC) where the Computer Engineering degree is taught in the day course and by meeting modalities, an exploratory study was carried out with the aim of determining the didactic treatment that It is given to the usability of software development in the race, for which the following questions were asked.

- Does the introduction of the subject "Usability in software development" in the university curriculum contribute to the training of a more competent professional in Computer Engineering careers?

- What results did the students who received the subject "Usability in software development" in the Computer Engineering degree at the University of Matanzas obtain in the development of their projects?

\section{Materials and Methods}

An exploratory study was carried out where a documentary review of the study plan E that governs the Computer Engineering career was carried out, as well as the analytical program of the discipline Engineering and Software Management of the respective study plan, where it was found that between the Optional curriculum subjects, generically suggest the subject "Software Quality", however there is none that specifically addresses usability in software development.

Interviews were conducted with the students of the regular daytime course belonging to the fourth and fifth years, where it was possible to verify the lack of knowledge on the subject, in this sense most of the students in their answers associated it with the quality of the software, but they could not provide many elements. Interviews were conducted with 26 teachers who teach different subjects in the discipline in order to verify the knowledge they had on the subject, denoting ambiguity in their responses, mainly aimed at highlighting usability in software development as an attribute of software quality and did not offer a more holistic approach to the topic addressed, the results are shown in figure 1. 


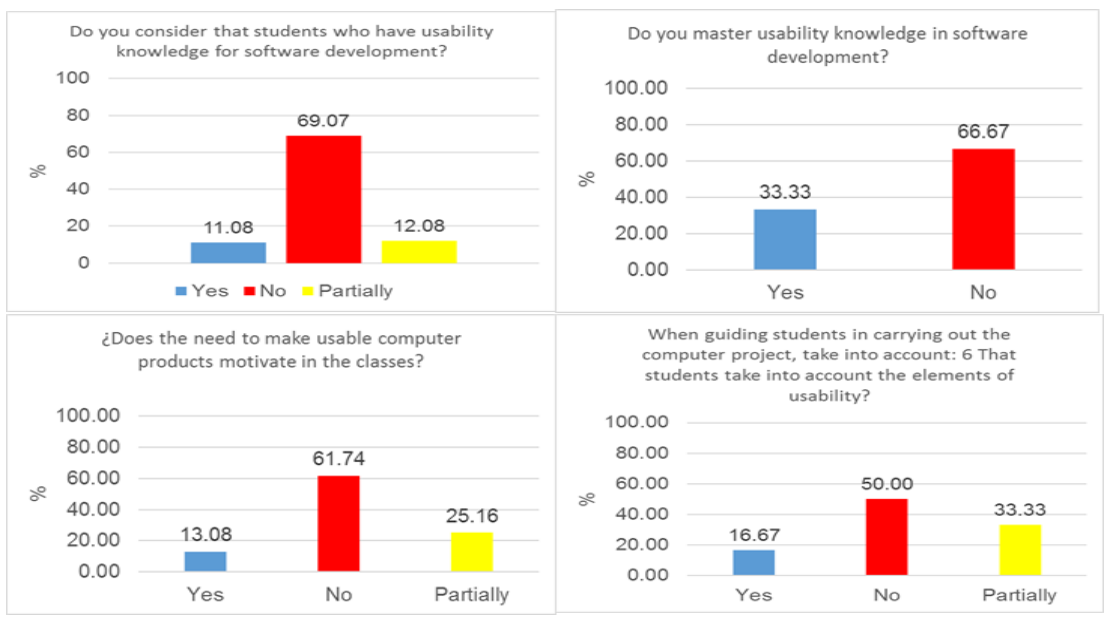

Fig. 1. Results of the survey carried out to 26 professors of the Computer Engineering degree

Once the previous diagnosis of the described situation had been carried out, the program for the subject "Usability in Software Development" was prepared and proposed to the Department of Computing at the University of Matanzas, which was reviewed by experts who validated it from the theoretical point view. Once validated and approved, the subject was taught as part of the optional curriculum that the 5th year students must receive to complete their professional training. This year was chosen because it has not received any subject related to the usability of the development of the software in previous years and it is the terminal year of the degree, where among the instructional objectives to be achieved, from the academic point of view, is the integration of the knowledge system of the future graduate; that, together with the diploma work, must constitute the integrative activity of the skills system, what would culminate the training of the engineer. The topics proposed for inclusion in the subject are shown in figure 2.

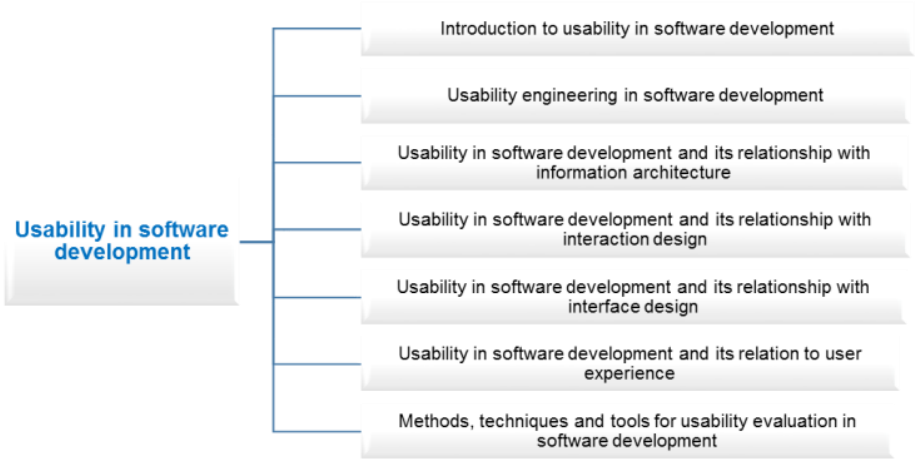

Fig. 2. The topics proposed for inclusion in the subject Usability in software development 
The proposed program has a duration of 42 hours, classes distributed in conferences, practical classes, seminars and workshops. The checklists created by [13] were used as a basic of teaching in the practical classes, adapting them to the context of the Computer Engineering career of the University of Matanzas so that the prototypes created by the students could be evaluated and they were provided with online tools to automate the tests.

\section{Results and Discussion}

Throughout the semester, the performance of the students in the subject was periodically evaluated, in addition, analyzes were made with the career and year groups, determining through integration the aspects and contents received in the subject "Usability in Software development" with the subject "Project seminar", which aims to prepare the student from the methodological point of view to successfully face the scientific and technical work that must be carried out during the execution of their Diploma Work. From this joint work, specific methodological indications were generated that made it possible to assess learning and combine theoretical aspects with practical elements. In this order of ideas, students had to present in the final evaluation the research protocol of their diploma work, as well as a prototype of the system they were developing. It is important to note that the presentation of the research protocol, as well as the design of the prototype, would be evaluated by the subject "Project seminar", because it was received by all students of the year and belongs to the curriculum itself. However, the aspects related to the subject "Usability in software development", as they belong to the elective / elective curriculum, only the students who received the subject were examined.

Nineteen papers were presented in the evaluation, of which 12 corresponded to the students who enrolled in the subject. Prior to the presentation of the prototypes on the day of the final evaluation, four prototypes were selected at a random. The first of those selected belonged to a student who took the course, the second prototype to those who did not receive it, the third and fourth prototypes belonged two students who were doing the same project but one received the subject and the other did not. The purpose of each selected prototype is shown in fig 3 .

\begin{tabular}{|c|c|c|}
\hline Prototype & Desoription & Information \\
\hline $\begin{array}{l}\text { Prototype } 1 \text { : System to manage the } \\
\text { Subsidy Procedure }\end{array}$ & $\begin{array}{l}\text { The purpose of this site is to manage } \\
\text { the housing subsidy processing } \\
\text { processes in the province of Matanzas }\end{array}$ & $\begin{array}{l}\text { The student who } \\
\text { developed the prototype } \\
\text { received the subject }\end{array}$ \\
\hline Prototype 2: EMERCAP: & $\begin{array}{l}\text { Computer system for the managemert } \\
\text { of training in the Company and training } \\
\text { in The Company for Dnilling and Capital } \\
\text { Repair of Ol and Gas Wells }\end{array}$ & $\begin{array}{l}\text { The student who } \\
\text { developed this prototype } \\
\text { does not receive a sibject }\end{array}$ \\
\hline \multicolumn{3}{|c|}{ This system is camed out wth the aim of improving the dissemination of university } \\
\hline Prototipo 3: Activate & \multirow{2}{*}{$\begin{array}{l}\text { This system is carried ou whth the aim } \\
\text { of improving the dissemination of } \\
\text { unversity events in university students at } \\
\text { the University of Matanzas. }\end{array}$} & $\begin{array}{l}\text { The student who } \\
\text { developed this prototype } \\
\text { received the subject }\end{array}$ \\
\hline Prototipo 4 :Activate & & $\begin{array}{l}\text { The student who made } \\
\text { this prototype did not } \\
\text { receive the course }\end{array}$ \\
\hline
\end{tabular}

Fig. 3. Selected prototypes prior to the final evaluation 
Following the international standard Iso / IEC 25040: 2010 (IEC, ISO / IEC 25040, 2010), the technique "Verification of the conformity of the user interface with standards"[5] for the evaluation of the usability in the selected prototypes is assumed. The applied technique, verification of compliance of the user interface with standards, required evaluation of the user interface design in the software. Subsequently, a Check List (LCH) was applied for verification [17], it was selected because it was based on the 78 usability criteria defined by [18], as it was an early phase of product development that was the stage where they were found. Students, the results of verifying the compliance of the user interface with standards are shown in the in figure 4.

\begin{tabular}{|c|c|c|c|c|c|c|c|c|c|c|c|c|}
\hline \multirow[b]{2}{*}{ Evaluation criteria } & \multicolumn{3}{|c|}{ Prototype 1} & \multicolumn{3}{|c|}{ Prototype 2} & \multicolumn{3}{|c|}{ Prototype 3} & \multicolumn{3}{|c|}{ Prototype 4} \\
\hline & \begin{tabular}{|c|} 
No. of \\
questions
\end{tabular} & $\begin{array}{l}\text { No. of } \\
\text { answers }\end{array}$ & \%ofgrade & $\mid \begin{array}{l}\text { No. of } \\
\text { question }\end{array}$ & $\begin{array}{l}\text { No. of } \\
\text { answers }\end{array}$ & \%o ofgrade & $\begin{array}{l}\text { No. of } \\
\text { questons }\end{array}$ & $\begin{array}{l}\text { No. of } \\
\text { answers }\end{array}$ & \% of grade| & $\begin{array}{l}\text { No. of } \\
\text { questions }\end{array}$ & $\begin{array}{l}\text { No. of } \\
\text { answers }\end{array}$ & Yofgrade \\
\hline Homepage & 20 & 20 & 100 & 20 & 14 & 70 & 20 & 19 & 95 & 20 & 13 & 65 \\
\hline $\begin{array}{l}\text { Taskorientifion and } \\
\text { sotware inctionalily }\end{array}$ & 29 & 28 & 97 & 20 & 14 & 70 & 29 & 26 & 90 & 29 & 21 & 72 \\
\hline $\begin{array}{l}\text { Navigabilityand } \\
\text { intrmation architedure }\end{array}$ & 23 & 23 & 79 & 29 & 13 & 45 & 23 & 21 & 91 & 23 & 11 & 48 \\
\hline Forms and data entry & 23 & 23 & 100 & 23 & 18 & 78 & 23 & 21 & 91 & 23 & 16 & 70 \\
\hline $\begin{array}{l}\text { Quailyof content and } \\
\text { writing }\end{array}$ & 23 & 21 & 91 & 23 & 18 & 78 & 23 & 23 & 100 & 23 & 16 & 70 \\
\hline $\begin{array}{l}\text { Diagramming and } \\
\text { graphical interbace }\end{array}$ & 38 & 37 & 97 & 38 & 32 & 84 & 38 & 36 & 95 & 38 & 32 & 84 \\
\hline Search & 20 & 20 & 100 & 20 & 20 & 100 & 20 & 20 & 100 & 20 & 20 & 100 \\
\hline Help kesback error & 37 & 35 & 95 & 37 & 30 & 81 & 37 & 34 & 92 & 37 & 35 & 95 \\
\hline Final score & 213 & 207 & 97 & 190 & 145 & 76 & 190 & 179 & 94 & 190 & 148 & 78 \\
\hline
\end{tabular}

Fig. 4. Evaluation technique: Verification of the conformity of the user interface with standards

The results obtained show that, the high levels of usability are manifested in the prototypes developed by the students who received the subject, the usability values range around $95 \%$, these are not negligible values, but undoubtedly indicate the need to continue the work in favor of usability through tests with users to evaluate their evaluation of each of the attributes of the usability characteristic, once the software has been used. The evaluation of the prototypes of the students who did not receive the subject oscillate around $77 \%$, presenting the main difficulties in aspects related to the navigability and architecture of information, quality of content and writing and layout and graphic interface, which denotes the need for studies of these contents related to usability that contributes to the quality of the software.

Figures 5 and 6 show prototypes 1 and 2 respectively, prototype 1 was prepared by the student who received the subject and prototype 2 was prepared by the student who did not receive the subject, where greater compliance with the parameters of usability, in prototype 1 compared to prototype 2 . 


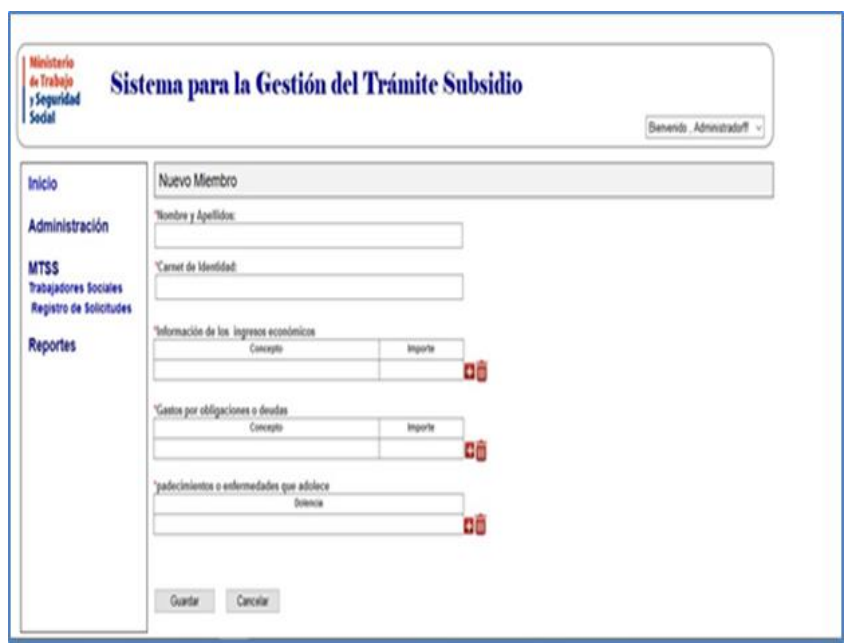

Fig. 5. Prototype 1: System to manage the Subsidy The student who developed this prototype received a subject

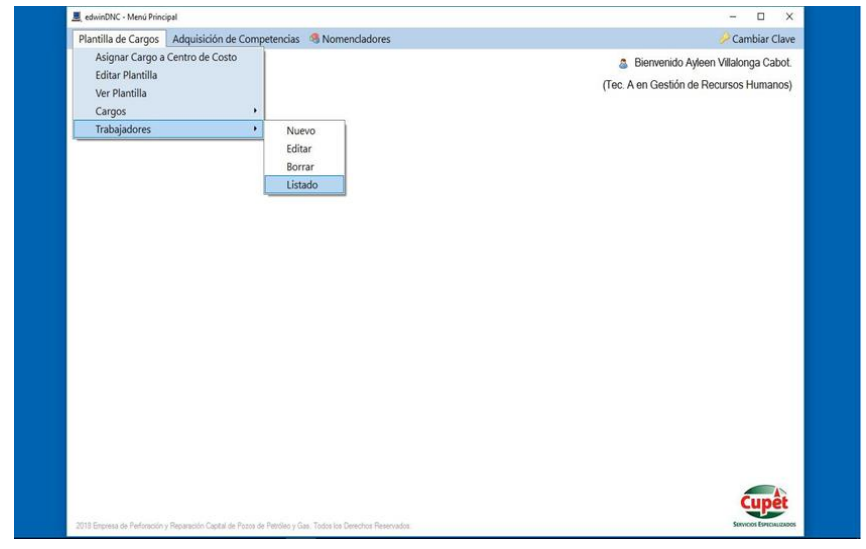

Fig. 6. Prototype 2 EMERCAP: Computer system for training management in the Oil Drilling Company prepared by a student who did not receive the course

Figure 7 shows two prototypes made by students who were working on the same project, prototype 3 was made by the student who received the subject and prototype 4 was made he tudent who did not receive the subject, observing that they are showing better usability parameters in prototype 3 compared to 4 . 


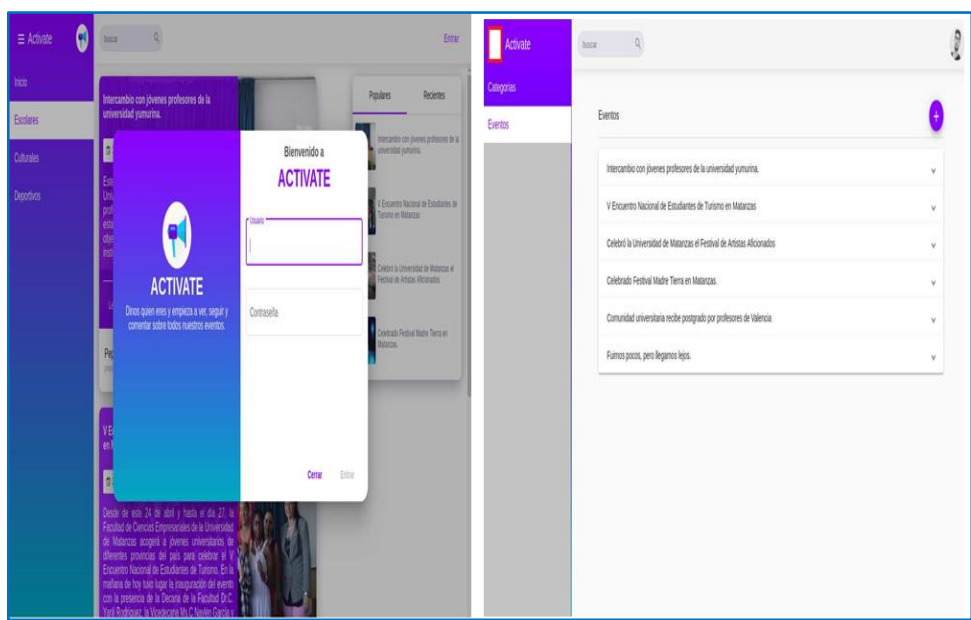

Prototype 3

Prototype 4

Fig. 7. Prototypes made by students who were working on the same project

During the development of the final evaluation, the students presented the research protocol and the prototype of the system they were developing. Once their exposition was concluded, each teacher of the subject evaluated the performance of each of the students. The teacher of the subject "Usability in software development" was presenting the results of the evaluation of the students carried out to the prototypes previously selected and offered evaluations and recommendations to those who did not receive the subject, others evaluated in a timely manner each of the students the knowledge acquired and the skills developed in classes. In general, all the students who received the subject observed a significant advance in the quality of their projects compared to those who did not receive it, and also expressed satisfaction and interest in all the elements treated, taking them into account to apply them to the systems that develop.

A survey was conducted to find out the criteria of the students on the topics covered in the subject, which reveals the level of motivation, satisfaction and dissatisfaction with the treatment that was given to usability elements necessary to develop higher quality projects. For its processing, the Iadov [14] technique was used, which facilitated the study, since the criteria used are based on the relationships established between three closed questions within the survey (questions 3, 5, and 10) and whose relationship the student unknown. These are related through what is called the Iadov Logical Table which is shown in the following figure 8 . 


\begin{tabular}{|c|c|c|c|c|c|c|c|c|c|}
\hline & \multicolumn{9}{|c|}{ 3. ¿Are you satisfied with making prototypes that have usability elements? } \\
\hline & \multicolumn{3}{|c|}{ Yes } & \multicolumn{4}{|c|}{ Idont know } & \multicolumn{2}{|l|}{ No } \\
\hline \multirow{2}{*}{$\begin{array}{l}10 \text { ¿Do you like to } \\
\text { use usability } \\
\text { knowledge in the } \\
\text { projects you } \\
\text { execute? }\end{array}$} & \multicolumn{9}{|c|}{$\begin{array}{l}\text { 5. ¿Would you be in a position to integrate usability elements into your projects after" } \\
\text { receiving the subject "Usability in software development develop it? }\end{array}$} \\
\hline & Yes & Idontknow & No & Yes & Idontknow & No & Yes & Idont know & No \\
\hline like verymuch & 1 & 2 & 6 & 2 & 2 & 6 & 6 & 6 & 6 \\
\hline like itmore thani dislike it & 2 & 2 & 3 & 2 & 3 & 3 & 6 & 3 & 6 \\
\hline Idoes not matter to me & 3 & 3 & 3 & 3 & 3 & 3 & 3 & 3 & 3 \\
\hline Idisilke itmore than like it & 6 & 3 & 6 & 3 & 4 & 4 & 3 & 4 & 4 \\
\hline Ido not like & 6 & 6 & 6 & 6 & 4 & 4 & 6 & 4 & 5 \\
\hline Idontknow & 2 & 3 & 6 & 3 & 3 & 3 & 6 & 3 & 4 \\
\hline
\end{tabular}

Fig. 8. Logical chart of Iadov

The number resulting from the interrelation of the three questions indicates the position of each student on the satisfaction scale. By applying the Iadov technique to know the level of satisfaction and dissatisfaction in the treatment given to usability elements, it was possible to know the position of each student on the individual satisfaction scale as shown in Table 1.

Table 1. Group satisfaction index measurement scale

\begin{tabular}{|l|c|c|}
\hline \multicolumn{1}{|c|}{ Classification } & From & Until \\
\hline Dissatisfaction & -1 & $-0,5$ \\
\hline Undefined or Contradictory & $-0,49$ & $+0,49$ \\
\hline Satisfaction & $+0,5$ & 1 \\
\hline
\end{tabular}

The analysis of the results found that of 12 surveyed students who received the subject, four have clear satisfaction, three are more satisfied than dissatisfied, and two are undefined, one more dissatisfied than satisfied, one with clear dissatisfaction and one with contradictory. When evaluating the group satisfaction index (ISG) it turned out to be 0.3 , which indicates clear satisfaction as shown in Table 2. 
Table 2. Levels of student satisfaction for the subject Usability in software development

\begin{tabular}{|l|c|c|}
\hline \multicolumn{1}{|c|}{ Selection } & Frequency & \% \\
\hline I am very satisfied & 4 & 33,33 \\
\hline More satisfied than dissatisfied & 3 & 25 \\
\hline I don't care & 2 & 16,6 \\
\hline More dissatisfied than satisfied & 1 & 16,1 \\
\hline Totally unsatisfied & 1 & 8.33 \\
\hline I don't know what to say & 1 & 8.33 \\
\hline Total & 12 & 100 \\
\hline
\end{tabular}

The answer to the questions to know the ways of thinking of the students in relation to the satisfaction when elaborating prototypes that represent elements of usability necessary for the projects they develop, confirm that: $81.3 \%$ answered affirmatively that they were satisfied It is satisfying to develop prototypes that have elements of usability, $11.5 \%$ do not know, $7.5 \%$ do not, in this sense, the students stated that what satisfies them the most is that they appropriate new usability knowledge in the development of the software which will be useful to make usable products, and what least satisfies you is the time to use to carry out the activity. $61.8 \%$ state that they were in a position to incorporate everything they had learnt about usability into their projects, from which it can be inferred that the assignment contributes significantly to the training of a more competent professional in Computer Engineering careers. 11.2\% answered that they were in a position to integrate usability elements into their projects after receiving the subject "Usability in software development, but they had to deepen their knowledge to reflect them in the preparation of their course projects. In relation to the question: Do you like to use usability knowledge in the projects you execute? $83.5 \%$ answered that they like it a lot, $12.7 \%$ like it more than they dislike it, $2.47 \%$ are indifferent, and $1.33 \%$ dislike it more than they like it. The results expressed above demonstrate in a general way the high significance that it represents for students to master the usability content for the realization of their course projects.

\section{Conclusion}

The exploratory study carried out on the teaching of usability in the development of software in the Computer Engineering degree showed the need to include the subject Usability in the development of software in the university curriculum, as its guide and concepts define a path to follow for reach parameters accepted in the international community as complements of the quality of the software, therefore it guarantees the preparation of the most competent professionals in the careers of computer engineering and emerges as an urgent and pertinent need today.

The teaching of usability in software development in the Computer Engineering degree at the University of Matanzas contributed to the achievement of sactifactorial results in the development of projects by the students, however the need to deepen these aspects is considered as well how to continue updating the course program where the 
end-user experience when interacting with the software is taken into account, among other issues, as a guarantee of product quality.

\section{$5 \quad$ References}

[1] R. Pressman, Software Engineering. A practical approach 7ma ed, 2010. Reading Mc Graw Hill Education, 2010. [E-book] Available: https://Cotana.informatica.edu.bo

[2] V. Chimarro, B. Mazón, and J. Cartuche, "Usability in software development," 2015. [Online]. Available: http://repositorio.utmachala.edu.ec. [Accessed: 12-Feb-2020].

[3] R. Miron, "Design and Evaluation of Usability Elements and User Experience Enhancements of a Gamified System for Computer Science Learning," Master Thesis, Polytechnic University of Madrid, 2019.

[4] M. Mascheroni, C. Greiner, G. Dapozo, and M. Estayno, "Usability Engineering. A Technological Proposal to Contribute to the Evaluation of Software Usability,” Lat. Am. J. Softw. Eng., vol. 1, no. 4, pp. 125-134, 2013. https://doi.org/10.18294/relais.2013.125-134

[5] D. Madruga and H. Viltres, "An evaluation of usability of software products: a practical case study,” Publishing, vol. 5, no. 3, pp. 525-541, 2018.

[6] R. Cuervo, "Evaluation of user experience in the Cuban context," Rev I+D Technological, vol. 15, no. 2, pp. 27-37, 2019.

[7] C. Carvajal, "Organizational Patterns for the Integration of Software Usability," Doctoral Thesis, University Polytechnic of Madrid Spain, 2019.

[8] International Organization for Standardization ISO 9126: Software Engineering - Product quality, Geneva, Switzerland. ISO 2001.

[9] International Organization for Standardization ISO 14598-1. Information Technology Evaluation of Software Products. General Guide. ISO 1998.

[10] ISO/IEC 25010:2011 Systems and software engineering - Systems and software Quality Requirements and Evaluation (SQuaRE) - System and software quality models. 2011. https://doi.org/10.3403/30215101

[11] A. N. d. P. Popular, 'Documents of the 7th. Party Congress approved by the III Plenum of the Central Committee of the CCP," La Habana, Cuba, 2017.

[12] Y. Lombida, "Procedure to incorporate Usability Engineering in the software development," Thesis, University of Informatics Sciences, Havana, Cuba, 2015.

[13] Y. Valle, A. Vázquez, and A. Vázquez, "Procedures for usability tests in the computer application based on ISO/IEC2500," Scientific Series, vol. 10, no. 11, pp. 13-23, Mar-2019.

[14] A. Fernandez de Castro, N. Sanchez, and Y. Reyes, "The validation process by means of the technique of Iadov in courses for encounters," Agric. Eng. Mag., vol. 10, no. 1, pp. 66-70, 2020.

[15] J. Pinto, V. Agredo, and C. Collazos, "Building a guide for the evaluation of usability in EVAs,” Virtual Campus, vol. 7, no. 2, pp. 93-104, 2018.

[16] J. Nielsen, "Usability Heuristics for User Interface Design." [Online]. Available: http://www.nngroup.com/articles/ten-usability-heuristics/. [Accessed: 15-Feb-2020].

[17] I. Leyva, "Procedure for the assurance and evaluation of usability based on architecturally sensitive patterns for the management systems of the Entity Management Computerization Center," Diploma Thesis, University of Informatics Sciences, Havana, Cuba, 2012.

[18] J. Nielsen, "Ten usability heuristics," 2005. [Online]. Available: https://pdfs.semanticssholar.org. [Accessed: 12-Feb-2020]. 
[19] D. A. Chen and G. D. Hoople, "Exploring Faculty and Student Frameworks for Engineering Knowledge Using an Online Card Sorting Platform,” IJEP, vol. 10, no. 1, pp. 62-81, 2020. https://doi.org/10.3991/ijep.v10i1.11336

[20] I. Atoum, "A Spiral Software Engineering Model to Inspire Innovation and Creativity of University Students," IJEP, vol. 9, no. 5, 2019. https://doi.org/10.3991/ijep.v9i5.10993

[21] P. Qvist et al., "Design of Virtual Learning Environments Learning Analytics and Identification of Affordances and Barriers," vol. 5, no. 4, pp. 49-62.

[22] E. Reyes, F. Fernandez, W. Perez, and P. Urrutia, “App Sigma and Facebook Groups: Evaluation the usability and Technology Acceptance by software Engineering Students of Ambator Technical University," Univ. Educ., vol. 1 1, no. 5, 2018. https://doi.org/10.4067/ $\underline{\text { S0718-50062018000500065 }}$

[23] C. Pribeanu, "A Revised Set of Usability Heuristics for the Evaluation of Interactive Systems," vol. 21, no. 3, pp. 31-38. https://doi.org/10.12948/issn14531305/21.3.2017.03

\section{Author}

Josue Segura, is a Doctor in Pedagogical Sciences graduated from the University of Matanzas, Cuba. He has worked in areas of Computer Science, with emphasis on its teaching-learning process, teaches in Computer Science careers and Bachelor's Degree in Computer Science Teaching in the Computer Science Department of the University of Matanzas and directs the management of computerization processes in the Young Computer and Electronics Club (YCEC), an institution in charge of computerizing $\mathrm{Cu}$ ban society. He is currently a researcher at the Technological Science Park of Matanzas. S.A (TSPM.S. A), a high-tech company, linked to the computerization of all processes in the province of Matanzas, Cuba.

Article submitted 2020-04-19. Resubmitted 2020-06-14. Final acceptance 2020-08-24. Final version published as submitted by the authors. 